\title{
OPERATOR VEC DAN VECH PADA MATRIKS
}

\author{
INDA SILVIA AFNI, YANITA, NOVA NOLIZA BAKAR \\ Jurusan Matematika, \\ Fakultas Matematika dan Ilmu Pengetahuan Alam, Universitas Andalas, \\ Kampus UNAND Limau Manis Padang, Indonesia, \\ email : Afniinda@gmail.com
}

\begin{abstract}
Abstrak. Tulisan ini membahas tentang sifat-sifat operator vec dan operator vech serta hubungan operator vec dengan hasilkali Kronecker dan matriks vec-permutasi. Teori yang diterapkan yaitu hubungan operator vec dan operator vech, hasilkali Kronecker dan matriks vec-permutasi.

Kata Kunci: Operator vec, operator vech, hasilkali Kronecker, matriks vec-permutasi
\end{abstract}

\section{Pendahuluan}

Operator vec dan operator vech adalah suatu operator yang terkait dengan aturan yang mengaitkan matriks $n \times n$ dengan matriks $m \times 1$. Pada operator vec matriks $n \times$ $n$ dikaitkan dengan matriks $n^{2} \times 1$, sedangkan operator vech yang simetri dikaitkan dengan matriks $\frac{1}{2} n(n+1) \times 1$

Tulisan ini membahas sifat-sifat operator vec dan operator vech pada matriks, serta hubungan operator vec dengan hasilkali Kronecker dan matriks vec-permutasi.

\section{Tinjauan Teori}

\subsection{Teori Matriks}

Definisi 2.1. [1] Suatu matriks (matrix) adalah jajaran empat persegi panjang dari bilangan-bilangan. Bilangan-bilangan dalam jajaran tersebut disebut entri dari matriks.

Definisi 2.2. [1] Ordo atau ukuran suatu matriks adalah ukuran matriks yang menyatakan banyak baris diikuti dengan banyak kolom.

Definisi 2.3. [1] Jika matriks $A$ dan $B$ adalah matriks-matriks dengan ukuran yang sama, maka jumlah $A+B$ adalah matriks yang diperoleh dengan cara menjumlahkan entri-entri pada $B$ dengan entri-entri yang bersesuaian dengan $A$ dan selisih $A-B$ adalah matriks yang diperoleh dengan mengurangkan entri-entri pada $A$ dengan entri-entri yang bersesuaian pada B.

Matriks dengan ukuran yang berbeda tidak dapat dijumlahkan atau dikurangkan.

Definisi 2.4. [1] Jika $A$ matriks berukuran $m \times r$ dan $B$ matriks berukuran $r \times n$ maka hasil kali $A B$ adalah matriks $m \times n$ yang entri-entrinya ditentukan sebagai 
berikut: untuk mencari entri pada baris $i$ dan kolom $j$ dari AB, di-pisahkan baris $i$ dari matriks $A$ dan kolom $j$ dari matriks B. Entri-entri yang bersesuaian dari baris dan kolom tersebut dikalikan, kemudian dijumlahkan hasil yang diperoleh.

Definisi 2.5. [1] Jika $A$ adalah matriks berukuran $m \times n$, maka transpos dari $A$, dinyatakan dengan $A^{T}$, diartikan sebagai matriks $n \times m$ yang didapatkan dengan mempertukarkan baris-baris dan kolom-kolom dari $A$, sehingga kolom pertama dari $A^{T}$ adalah baris pertama dari $A$, kolom kedua dari $A^{T}$ adalah baris kedua dari $A$, dan seterusnya.

Teorema 2.6. [1] Misalkan matriks $A$ dan $B$ berukuran sedemikian rupa sehingga operasi-operasi berikut dapat dilakukan dan misalkan $k$ adalah skalar, maka:

(a) $\left((A)^{T}\right)^{T}=A$.

(b) $(A+B)^{T}=A^{T}+B^{T}$ dan $(A-B)^{T}=A^{T}-B^{T}$.

(c) $(k A)^{T}=k A^{T}$ dengan $k$ adalah skalar sebarang.

(d) $(A B)^{T}=B^{T} A^{T}$.

Definisi 2.7. [1] Misalkan A adalah matriks bujursangkar yang elemennya simetri secara diagonal, maka matriks simetri dinyatakan sebagai matriks yang transposnya sama dengan dirinya sendiri.

Definisi 2.8. [1] Suatu matriks berukuran $n \times n$ dikatakan matriks identitas, apabila elemen diagonal utamanya bernilai 1 dan elemen yang lainnya bernilai 0. Matriks identitas berukuran $n \times n$ disimbolkan dengan $I_{n}$.

Definisi 2.9. [1] Jika $A$ adalah matriks bujursangkar, dan jika terdapat matriks $B$ yang ukurannya sama sedemikian rupa sehingga $A B=B A=I$, maka $A$ disebut dapat dibalik (invertible) dan $B$ disebut sebagai invers (inverse) dari A. Jika matriks $B$ tidak dapat didefinisikan, maka $A$ dinyatakan sebagai matriks singular.

\subsection{Hasilkali Kronecker}

Definisi 2.10. [9] Misalkan matriks $A=\left[a_{i j}\right]$ berukuran $m \times n$ dan matriks $B=\left[b_{k l}\right]$ berukuran $p \times q$, maka hasilkali Kronecker dari matriks $A$ dan matriks $B$ dinyatakan sebagai

$$
\begin{aligned}
A \otimes B & =\left[\begin{array}{cccc}
a_{11} B & a_{12} B & \cdots & a_{1 n} B \\
a_{21} B & a_{22} B & \cdots & a_{2 n} B \\
\vdots & \vdots & \ddots & \vdots \\
a_{m 1} B & a_{m 2} & \cdots & a_{m n} B
\end{array}\right] \in \mathbb{C}^{m p \times n q} \\
& =\left[a_{i j} B\right] .
\end{aligned}
$$

Teorema 2.11. [3] Misalkan $A \in \mathbb{C}^{m \times n}, B \in \mathbb{C}^{p \times q}, C \in \mathbb{C}^{r \times s}, X \in \mathbb{C}^{n \times p}$, $Y \in \mathbb{C}^{r \times s}$, serta $\boldsymbol{x}$ dan $\boldsymbol{y}$ merupakan vektor kolom sebarang maka :

(1) $(A \otimes B) \otimes C=A \otimes(B \otimes C)$.

(2) $A \otimes(B+C)=(A \otimes B)+(A \otimes C)$. 
(3) $(A \otimes B)^{T}=A^{T} \otimes B^{T}$.

(4) $(A \otimes B)(X \otimes Y)=A X \otimes B Y$.

(5) $(A \otimes B)^{-1}=A^{-1} \otimes B^{-1}$.

(6) $\left(\boldsymbol{x} \otimes \boldsymbol{y}^{T}\right)=\left(\boldsymbol{y}^{T} \otimes \boldsymbol{x}\right)=\boldsymbol{x} \boldsymbol{y}^{T}$.

\section{Operator Vec dan Operator Vech}

Definisi 3.1. [3] Misalkan $X=\left[x_{1} x_{2} \cdots x_{n}\right] \in \mathbb{C}^{m \times n}$, dimana $x_{j} \in \mathbb{C}^{m}, j=$ $1,2, \cdots, n$, maka $\boldsymbol{v e c}(X)$ dinyatakan sebagai

$$
\boldsymbol{v e c}(X)=\left[\begin{array}{r}
x_{1} \\
x_{2} \\
\vdots \\
x_{n}
\end{array}\right] .
$$

Teorema 3.2. [9],[8] Misalkan $A \in \mathbb{C}^{m \times n}$ dan $B \in \mathbb{C}^{n \times p}$, maka

$$
\left(I_{p} \otimes A\right) \operatorname{vec}(B)=\left(B^{T} \otimes I_{m}\right) \operatorname{vec}(A)=\operatorname{vec}(A B) .
$$

Definisi 3.3. [2] Misalkan sebarang matriks simetri $X=\left[x_{i j}\right] \in \mathbb{C}^{n \times n}$. Vektor $\operatorname{vech}(X) \in \mathbb{C}^{\frac{1}{2} n(n+1)}$ dinyatakan sebagai

$$
\operatorname{vech}(X)=\left[\begin{array}{r}
x_{11} \\
\sqrt{2} x_{12} \\
\vdots \\
\sqrt{2} x_{1 n} \\
x_{22} \\
\sqrt{2} x_{23} \\
\vdots \\
\sqrt{2} x_{2 n} \\
\vdots \\
x_{n n}
\end{array}\right]
$$

Definisi 3.4. [6] Untuk sebarang matriks simetri $X=\left[x_{i j}\right] \in \mathbb{C}^{n \times n}$, dinyatakan $H=\left[h_{r s}\right] \in \mathbb{C}^{\frac{1}{2} n(n+1) \times n^{2}}$ sebagai

$$
H=\left[\begin{array}{ccccccccc}
x_{11} x_{11}^{*} & x_{11} x_{12}^{*} & \cdots & x_{11} x_{1 n}^{*} & x_{11} x_{12}^{*} & \cdots & x_{11} x_{2 n}^{*} & \cdots & x_{11} x_{n n}^{*} \\
x_{12} x_{11}^{*} & x_{12} x_{12}^{*} & \cdots & x_{12} x_{1 n}^{*} & x_{12} x_{12}^{*} & \cdots & x_{12} x_{2 n}^{*} & \cdots & x_{12} x_{n n}^{*} \\
\vdots & \vdots & \ddots & \vdots & \vdots & \ddots & \vdots & \ddots & \vdots \\
x_{1 n} x_{11}^{*} & x_{1 n} x_{12}^{*} & \cdots & x_{1 n} x_{1 n}^{*} & x_{1 n} x_{12}^{*} & \cdots & x_{1 n} x_{2 n}^{*} & \cdots & x_{1 n} x_{n n}^{*} \\
x_{22} x_{11}^{*} & x_{22} x_{12}^{*} & \cdots & x_{22} x_{1 n}^{*} & x_{22} x_{12}^{*} & \cdots & x_{22} x_{2 n}^{*} & \cdots & x_{22} x_{n n}^{*} \\
\vdots & \vdots & \ddots & \vdots & \vdots & \ddots & \vdots & \ddots & \vdots \\
x_{2 n} x_{11}^{*} & x_{2 n} x_{12}^{*} & \cdots & x_{2 n} x_{1 n}^{*} & x_{2 n} x_{12}^{*} & \cdots & x_{2 n} x_{2 n}^{*} & \cdots & x_{2 n} x_{n n}^{*} \\
\vdots & \vdots & \ddots & \vdots & \vdots & \ddots & \vdots & \ddots & \vdots \\
x_{n n} x_{11}^{*} & x_{n n} x_{12}^{*} & \cdots & x_{n n} x_{1 n}^{*} & x_{n n} x_{12}^{*} & \cdots & x_{n n} x_{2 n}^{*} & \cdots & x_{n n} x_{n n}^{*}
\end{array}\right],
$$


dimana $h_{r s}=x_{i j} x_{k l}^{*}$ dengan $x_{i j}$ entri-entri pada $\operatorname{vech}(X)$ dan $x_{k l}^{*}$ entri-entri pada $\boldsymbol{v e c}(X)$, yang memenuhi

$$
x_{i j} x_{k l}^{*}= \begin{cases}1, & \text { jika } i=j=k=l \\ \frac{1}{\sqrt{2}}, & \text { jika } i=k \neq j=l \text { atau } i=l \neq j=k, \\ 0, & \text { selainnya. }\end{cases}
$$

Definisi 3.5. [9] Misalkan $e_{i n}$ adalah sebuah vektor kolom n-tuple yang bernilai 1 pada posisi ke-i dan 0 selainnya, maka

$$
e_{i n}=[0,0, \cdots, 0,1,0, \cdots, 0]^{T} .
$$

Berdasarkan Definisi 3.5, matriks identitas dapat dituliskan sebagai

$$
I_{n}=\left[e_{1 n} e_{2 n} \cdots e_{n n}\right] .
$$

Definisi 3.6. [9] Suatu matriks vec-permutasi $P_{m n}$ dinyatakan sebagai berikut

$$
P_{m n}=\left[\begin{array}{c}
I_{m} \otimes e_{1 n}^{T} \\
I_{m} \otimes e_{2 n}^{T} \\
\vdots \\
I_{m} \otimes e_{n n}^{T}
\end{array}\right] \in \mathbb{R}^{m n \times m n} .
$$

\subsection{Sifat-Sifat Operator Vec dan Operator Vech}

Teorema 3.7. [4] Misalkan $H \in \mathbb{C}^{\frac{1}{2} n(n+1) \times n^{2}}$ dengan $G$ merupakan transpos dari $H$ dan $P_{n n}$ merupakan matriks vec-permutasi, maka

(1) $H G=I_{\frac{1}{2} n(n+1)}$.

(2) $H=\left(G^{T} G\right)^{-1} G^{T}$.

(3) $P_{n n} G=G$.

(4) $H P_{n n}=H$.

Teorema 3.8. [4] Misalkan matriks simetri $X=\left[x_{i j}\right] \in \mathbb{C}^{n \times n}$ dan $H \in \mathbb{C}^{\frac{1}{2} n(n+1) \times n^{2}}$ dengan $G$ merupakan transpos dari $H$, maka

(1) $\operatorname{vech}(X)=H \operatorname{vec}(X)$.

(2) $\operatorname{vec}(X)=G \operatorname{vech}(X)$.

(3) $\operatorname{vech}(X)=H G \operatorname{vech}(X)$.

\subsection{Operator Vec dengan Hasilkali Kronecker dan Matriks} Vec-permutasi

Teorema 3.9. [3] Misalkan $A \in \mathbb{C}^{n \times n}$ dengan $A$ nonsingular, maka

$$
\boldsymbol{v e c}\left(A^{-1}\right)=\left(\left(A^{-1}\right)^{T} \otimes A^{-1}\right) \boldsymbol{v e c}(A) .
$$

Bukti. Misalkan $A \in \mathbb{C}^{n \times n}$ dengan $A$ nonsingular, akan ditunjukkan

$$
\operatorname{vec}\left(A^{-1}\right)=\left(\left(A^{-1}\right)^{T} \otimes A^{-1}\right) \operatorname{vec}(A) .
$$


74 Inda Silvia Afni dkk.

Perhatikan bahwa:

$$
\begin{array}{rlrl}
\operatorname{vec}\left(A^{-1}\right) & =\operatorname{vec}\left(\left(A^{-1} A\right) A^{-1}\right) & \\
& =\left(\left(A^{-1}\right)^{T} \otimes I_{n}\right) \operatorname{vec}\left(A^{-1} A\right) & & (\text { Teorema } 3.2) \\
& =\left(\left(A^{-1}\right)^{T} \otimes I_{n}\right)\left(I_{n} \otimes A^{-1}\right) \operatorname{vec}(A) & & (\text { Teorema } 3.2) \\
& =\left(\left(A^{-1}\right)^{T} I_{n}\right) \otimes\left(I_{n} A^{-1}\right) \operatorname{vec}(A) & & (\text { Teorema } 2.11) \\
& =\left(\left(A^{-1}\right)^{T} \otimes A^{-1}\right) \operatorname{vec}(A), &
\end{array}
$$

Jadi, $\operatorname{vec}\left(A^{-1}\right)=\left(\left(A^{-1}\right)^{T} \otimes A^{-1}\right) \operatorname{vec}(A)$.

Teorema 3.10. [4] Misalkan matriks simetri $X=\left[x_{i j}\right] \in \mathbb{C}^{n \times n}$, maka untuk $X=X^{T}$ berlaku

$$
\operatorname{vec}\left(X^{T}\right)=P_{n n} \operatorname{vec}(X)=\operatorname{vec}(X)
$$

\section{Kesimpulan}

Dari pembahasan yang telah dilakukan, diperoleh kesimpulan sebagai berikut: Misalkan $X=\left[x_{i j}\right] \in \mathbb{C}^{n \times n}$ adalah matriks simetri dan $H \in \mathbb{C}^{\frac{1}{2} n(n+1) \times n^{2}}$, diperoleh:

(1) Misalkan $G$ merupakan transpos dari $H$ dan $P_{n n}$ didefinisikan sebagai

$$
P_{n n}=\left[\begin{array}{c}
I_{n} \otimes e_{1 n}^{T} \\
I_{n} \otimes e_{2 n}^{T} \\
\vdots \\
I_{n} \otimes e_{n n}^{T}
\end{array}\right] \in \mathbb{R}^{n n \times n n} .
$$

maka
(a) $H G=I_{\frac{1}{2} n(n+1)}$.
(b) $H=\left(G^{T} G\right)^{-1} G^{T}$.
(c) $P_{n n} G=G$.
(d) $H P_{n n}=H$.

(2) Misalkan operator vec dan operator vech didefinisikan sebagai berikut

$$
\operatorname{vech}(X)=\left[\begin{array}{r}
x_{11} \\
\sqrt{2} x_{12} \\
\vdots \\
\sqrt{2} x_{1 n} \\
x_{22} \\
\vdots \\
\sqrt{2} x_{2 n} \\
\vdots \\
x_{n n}
\end{array}\right] \quad \text { dan } \operatorname{vec}(X)=\left[\begin{array}{r}
x_{11} \\
\vdots \\
x_{n 1} \\
x_{12} \\
\vdots \\
x_{n 2} \\
\vdots \\
x_{1 n} \\
\vdots \\
x_{n n}
\end{array}\right],
$$

maka sifat-sifat dari operator vec dan operator vech adalah

(a) $\operatorname{vech}(X)=H \operatorname{vec}(X)$. 
(b) $\operatorname{vec}(X)=G \operatorname{vech}(X)$.

(c) $\operatorname{vech}(X)=H G \operatorname{vech}(X)$.

(3) Misalkan $A \in \mathbb{C}^{n \times n}$ dengan $A$ nonsingular, maka hubungan operator vec dengan hasilkali kronecker adalah

$$
\operatorname{vec}\left(A^{-1}\right)=\left(\left(A^{-1}\right)^{T} \otimes A^{-1}\right) \operatorname{vec}(A) .
$$

(4) Misalkan $X \in \mathbb{C}^{n \times n}$, maka hubungan operator vec dengan matriks vecpermutasi adalah

$$
\operatorname{vec}\left(X^{T}\right)=P_{n n} \operatorname{vec}(X)=\operatorname{vec}(X)
$$

\section{Ucapan Terima Kasih}

Penulis mengucapkan terima kasih kepada bapak Mahdhivan Syafwan, bapak Admi Nazra dan bapak Zulakmal yang telah memberikan masukan dan saran sehingga makalah ini dapat diselesaikan dengan baik.

\section{Daftar Pustaka}

[1] Anton, H. dan Rorres, C. 2004. Aljabar Linear Elementer; edisi ke-8. Erlangga, Jakarta.

[2] E. de Klerk. 2002. Aspects of Semidefinite Programming. Kluwer Academic, Amsterdam.

[3] Harville, D.A. 2008. Matrix Algebra from a Statistician's Perspective. Springer, New York.

[4] Henderson, H. V. dan Searle, S. R. 1979. Vec and Vech Operators for Matrices, with Some Uses in Jacobians and Multivariate Statistic. Canad. J. Statist. 7, $65-81$

[5] Laub, A. J. 2005. Matrix Analysis for Scientist and Engineers. Society for Industrial and Applied Mathematics (SIAM), Wasington, D.C.

[6] M.J. Todd, K.C. Toh dan R.H. Tutuncu. 1998. On the NesterovTodd Direction in Semidefinite Programming. SIAM J. Optim., 8-3:769796

[7] Noble, Ben and Daniel, J. W. 1998. Applied Linier Algebra 3th Edition. Prentice-Hall, New Jersey.

[8] Rao, C. R and Rao, M. B. 1998. Matrix Algebra and Its Applications to Statistics and Econometrics. World Scientific, Singapore.

[9] Zhang, H dan Ding F. 2013. On the kronecker product and their applications. Journal of Applied Mathematics. 296185: $1-8$ 